\begin{tabular}{|l|l|}
\hline JURNAL ABDI MASYA & $\begin{array}{l}\text { Volume 1 Nomor 3 } \\
\text { November 2021 } \\
\text { pp 149-156 } \\
\text { Website: } \text { https://jurnal.sttw.ac.id/index.php/abma/about } \\
\text { E-ISSN : 2774-2849 } \\
\text { P-ISSN : 2774-2881 }\end{array}$ \\
\hline
\end{tabular}

\title{
PENERAPAN PENGECATAN POWDER COATING FLUIDS PADA PERBAIKAN GEROBAK SAMPAH DI KELURAHAN SERENGAN SURAKARTA
}

\section{APPLICATION OF POWDER COATING FLUIDS PAINT ON WASTE CART REPAIR AT SURAKARTA SERENGAN NEIGHBORHOOD}

\author{
Joko Yunianto Prihatin ${ }^{1 *}$, Slamet Pambudi², Heri Kustanto ${ }^{3}$, Lujeng Widodo4, Aris Joko \\ Saraswo ${ }^{5}$ \\ 1,2,3,4 Sekolah Tinggi Teknologi Warga Surakarta, Surakarta, Indonesia \\ ${ }^{5}$ Posyantek Kecamatan Serengan, Surakarta, Indonesia \\ *Email: jokoyp.atw@gmail.com
}

\begin{abstract}
ABSTRAK
Gerobak sampah merupakan sarana kebersihan yang berfungsi mengangkut sampah lingkungan masyarakat kelurahan serengan pada khususnya. Alat tersebut bermanfaat kepada kesehatan lingkungan bisa terhindar dari polusi udara. Dewasa ini penggunaan gerobak sampah lebih tinggi dari pada perawatannya. Permasalahan yang terjadi dewasa ini di wilayah lingkungan potrojayan dikelurahan serengan khususnya adalah bahwa gerobak sampah lebih cepat waktunya mengalami pengelupasan cat dan alasnya keropos dari standar pemakaian 5 tahun. Ada 2 gerobak sampah yang dalam kondisi rusak, keropos dan tidak layak pakai. Pada kegiatan ini bertujuan untuk melakukan perbaikan kondisi gerobak sampah yang dititik beratkan kepada pengecatan serbuk. Metode pelaksanaan pengabdian masyarakat ini meliputi survei di kelurahan serengan, pembongkaran, pengelasan dan pengecatan sistem serbuk. Hasil yang dicapai dari kegiatan ini adalah 2 gerobak sampah yang sudah diperbaiki dan layak pakai, dan menyerahkan kembali ke petugas sampah untuk dioperasikan secara nyaman dan aman serta sehat. Waktu yang diperlukan untuk proses perbaikan alas dan pengecatan sistem powder coating pada 2 buah gerobak sampah tersebut adalah 7 jam
\end{abstract}

Kata Kunci : gerobak sampah, pengecatan serbuk, buang sampah,

\begin{abstract}
Garbage cart is a cleaning facility that functions to transport environmental waste from the Serengan Village community in particular. This unit is useful for environmental health and can avoid air pollution. Nowadays the use of garbage carts is higher than maintenance. The problem that occurs today in the potrojayan neighborhood in the Serengan sub-district in particular is that the garbage cart has a faster time to experience paint peeling and the base is porous than the standard 5 year usage.There are 2 garbage carts that were damaged, porous and unfit for use. This activity aims to improve the condition of the garbage cart, which focuses on powder painting. The method of implementing this community service includes surveys in the Serengan Village, demolition, welding and painting of the powder system. The results achieved from this activity are 2 garbage carts that have been repaired and are fit for use, and handed back to the garbage officers to be operated in a comfortable and safe and healthy manner. The time required for the process of repairing the base and painting the powder coating system on the 2 garbage carts is 7 hours.
\end{abstract}

Keywords : garbage cart, powder painting, throw garbage.

Submit: 29 Oktober 2021 Accepted: 12 November 2021 Published: 26 November 2021 


\section{PENDAHULUAN}

Menurut Supriyono [1]. Powder coating merupakan proses pelapisan pada permukaan logam dengan suatu lapisan film, kemudian dipanaskan untuk polimerisasi dan mengawetkan coating. Partikel yang bermuatan negatif disemprotkan ke benda kerja untuk mencapai daya rekat serta ketahan korosi yang maksimal. Juga menurut Islahudin $\mathrm{N}$ [2]. Teknologi pelapisan yang digunakan bagian painting plastik adalah teknologi atomisasi. Teknologi ini merupakan teknologi pelapisan dengan cara merubah cairan material menjadi kabut atau butiran yang digunakan untuk melapisi produk. Ariany Z [3]. Pengecatan adalah salah satu hal sangat penting pada reparasi lambung kapal. Hal ini dilakukan untuk menghindarkan pelat dari karat atau korosi. Kajian ini dilakukan untuk menghitung konsumsi cat pada kegiatan reparasi lambung Kapal. Pada kajian ini mengambil studi kasus reparasi lambung pada kapal KM. Kirana 3, dilakukan dengan menghitung/estimasi konsumsi cat yang digunakan.

Santoso D [4]. Analisa dan evaluasi jumlah peralatan persampahan di keurahan pucang sawit kota surakarta. Gerobak sampah yang digunakan hanyalah gerobak sampah manual (dorong), sepenuhnya menggunakan tenaga manusia, oleh karena itu dirasa kurang efisien. Kelurahan Pucang Sawit untuk saat ini memerlukan tambahan gerobak sampah sebanyak 12 buah gerobak manual untuk melayani seluruh sampah yang dihasilkan masyarakat, dan sebaiknya menambahkan 1 buah gerobak sampah bermotor. Atmaji D.P [5]. Untuk mencegah korosi adalah dengan proteksi katodik, bahkan pasti dilakukan proteksi ganda atau penggunaan bersama antara coating dengan proteksi katodik ini atau yang sering digunakan bersama Impressed Current Cathodic Protection (ICCP).

Muhammad M M [6]. Dalam penelitian ini, untuk memaksimalkan fungsi pelapis dengan tujuan memberikan penghalang antara material dengan lingkungan, digunakan ketebalan coating (50, 100, 150, 200, dan 250 mikron). Sedangkan untuk mempermudah proses aplikasi dilakukan penambahan pelarut $0 \%, 10 \%$, dan $20 \%$. Cat primer yang digunakan adalah epoksi untuk melapisi material substrat ASTM A36 Grade B pada lingkungan air laut. Proses aplikasi menggunakan metode conventional spray. Morfologi dari hasil coating diamati dengan SEM. Untuk mengetahui kualitas dari coating, dilakukan pengujian daya lekat, tingkat bistering, dan ketahanan terhadap pelebaran kerusakan karena korosi serta besar perambatan uap air melalui cat.

Kelurahan Serengan berlokasi di kecamatan Serengan Kota Surakarta yang memiliki kode pos 57155. Di kelurahan Serengan terdapat sebuah pondok pesantren yang termasuk pondok pesantren paling tua di pulau Jawa, yakni pondok pesantren Jamsaren. Pada masa perang kemerdekaan (Clash II) beberapa lokasi di kelurahan Serengan menjadi ajang pertempuran yang memakan banyak korban sipil, saat ini di lokasi-lokasi tersebut dibangun monumen untuk mengingat peristiwa tersebut. di antaranya monumen juang di Jalan Veteran, Makam Bergola; bahkan di rumah warga masih didapati tanah yang berlubang akibat bekas bom yang dijatuhkan oleh pesawat tempur NICA. di kelurahan serengan juga terdapat makam kuno yang dipercayai peninggalan kerajaan Pengging, yakni di kampung Potrojayan. Batas wilayah kelurahan ini dijelaskan pada gambar peta dibawah ini. 


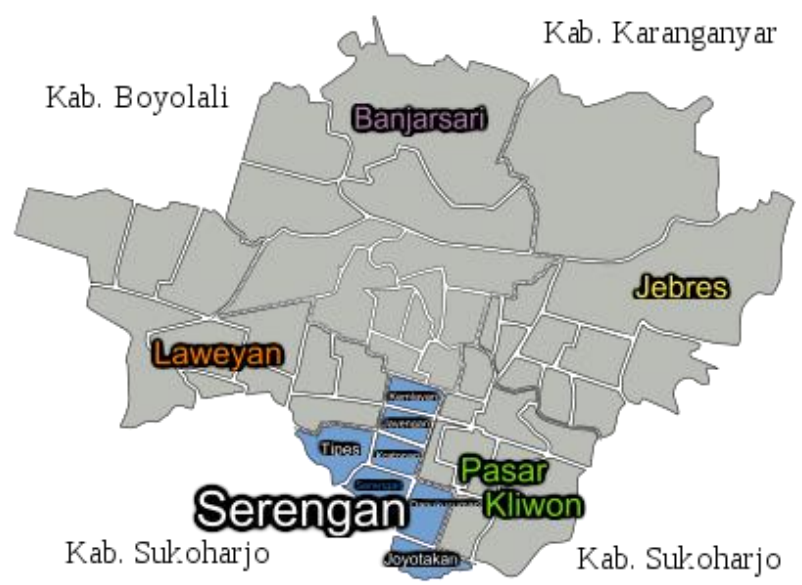

Gambar 1. peta wilayah kelurahan serengan kecamatan serengan kota surakarta

Kelurahan serengan terbagi menjadi 8 wilayah yaitu brondongan, dawung wetan, dawung tengah, kartotiyasan, makam, potrojayan, serengan dan sraten. Wilayah potrojayan merupakan paling banyak penduduknya dengan memiliki jumlah 8 buah gerobak sampah juga terbanyak. Terdapat 2 gerobak sampah yang rusak dan tidak layak dipakai dari segi keamanan dan kesehatan.

Menurut Santoso D [4]. Gerobak sampah banyak dioperasikan oleh petugaspetugas kebersihan atau tim oranye baik yang dipekerjakan oleh pihak pemerintah maupun pihak swasta. Gerobak sampah berfungsi untuk pengangkut sampah yang didesain dengan roda dan bak sampah yang mudah dimasukkan ke dalam truk pengangkut sampah. Hal ini memudahkan pengangkutan sampah baik dari lingkungan masyarakat, wilayah perumahan, fasilitas umum, dan industri. Penggunaan gerobak sampah juga menguntungkan bagi masyarakat karena dalam sekali pengangkutan sampah, jumlah muatan sampah sangat banyak. Selain itu dalam mengangkut sampah lebih mudah dan efisien. Penggunaan gerobak sampah juga memberikan banyak pemanfaatannya dalam kehidupan sehari-hari diantaranya untuk menghindarkan dari hama sampah, mengurangi polusi udara, mencegah sampah berserakan, juga sebagai edukasi masyarakat tentang buang sampah pada tempatnya.

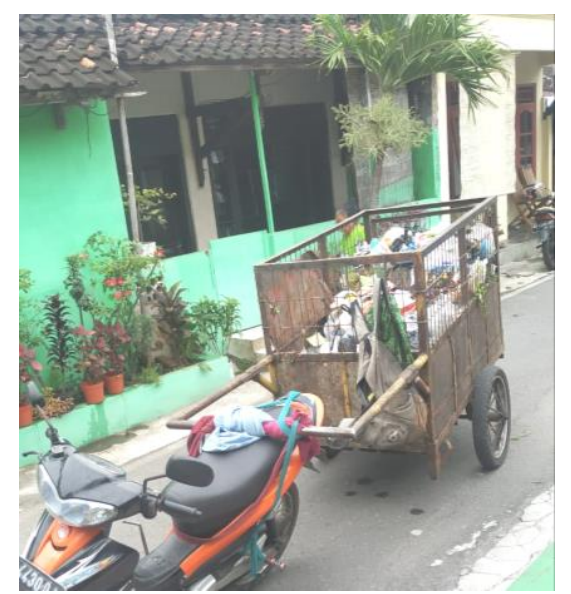

Gambar 2. permasalahan kondisi kerusakan gerobak sampah di kelurahan serengan

Dijelaskan pada gambar diatas ini, adalah permasalahan gerobak sampah manual di wilayah potrojayan kelurahan serengan. Permasalahan yang terjadi dewasa ini di wilayah 
lingkungan potrojayan dikelurahan serengan khususnya adalah bahwa gerobak sampah lebih cepat waktunya mengalami pengelupasan cat dan alasnya keropos dari standar pemakaian 5 tahun. Salah satu penyebab utamanya adalah peningkatan pembuangan sampah tidak sebanding dengan peralatan yang disediakan. Sehingga kapasitas angkut dari gerobak sampah menjadi kelebihan beban dan cepat rusak. Bahkan ketika musim penghujan dan banyak sampah yang masih basah mengakibatkan beban yang ditumpu gerobak sampah menjadi bertambah.

Berdasarkan permasalahan kondisi kerusakan keropos dan pengelupasan cat tersebut, juga disamping program perbaikan gerobak dari pihak kelurahan belum mampu segera bisa dilaksanakan. Maka tim kegiatan pengabdian masyarakat STTW bersama mitra (Pos pelayanan Teknologi) Posyantek Cipta Karya Kecamatan Serengan ini berupaya dalam hal perbaikan alas dan pengecatan gerobak sampah dengan menerapkan powder coating. Tujuan utama kegiatan ini adalah untuk menentukan waktu yang diperlukan untuk proses perbaikan alas dan pengecatan sistem powder coating pada 2 buah gerobak sampah tersebut dan menyerahkannya kembali untuk dimanfaatkan.

\section{METODE}

Kegiatan pengabdian masyarakat antara tim P2M STTW bersama Posyantek Kecamatan Serengan ini di dilaksanakan di bengkel Posyantek Cipta Karya wilayah kelurahan Serengan. Sehingga evaluasi pengerjaan, penyerahan, serta pemeliharaannya menjadi efisien. Pelaksanaan pengujian dan perbaikan pada bulan maret tahun 2021 selama 2 minggu. Tahapan kegiatan pengabdian tersebut dijelaskan pada gambar diagram alir perbaikan gerobak sampah dibawah ini.

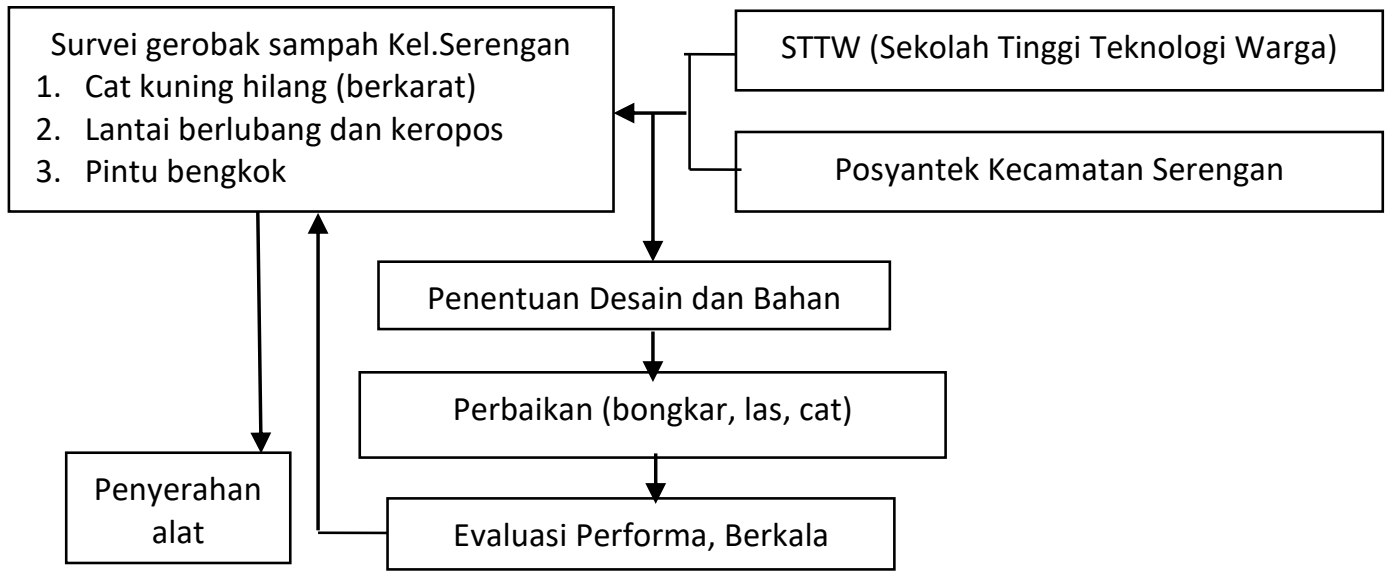

Gambar 3. Diagram alir pengabdian perbaikan gerobak sampah kelurahan serengan adalah:

Teknis pelaksanaan kegiatan pengabdian ini meliputi banyak tahapan diantaranya

1. Tim pelaksana yang terdiri dari tim Pengabdian Masyarakat STTW dan mitra lembaga posyantek melakukan survei dan diskusi ke organisasi ketua kelurahan serengan, juga kepada petugas sampah untuk mencari informasi permasalahan pengelolaan gerobak sampah.

2. Tim pelaksana mengadakan penentuan desain dan pemilihan bahan pada konsep perbaikan gerobak sampah. 
3. Pelaksanaan pembongkaran gerobak sampah yang rusak dan dilakukan perbaikan pengelasan penguatan dan dilanjutkan finishing pengecatan.

4. Dilakukan pengujian dengan dibebani dan tanpa dibebani selama 1 minggu oleh petugas sampah.

5. Jika permasalahan kerusakan sudah mampu diselesaikan, maka dilakukan penyerahan alat ke pihak kelurahan serengan dan evaluasi kinerja alat secara berkala tetap dilakukan.

Tahapan yang dilaksanakan pada perbaikan 2 gerobak sampah yang rusak ini adalah meliputi

1. Pre inspection merupakan awal terhadap permukaan material yang akan di cat dengan tujuan agar diperoleh perekatan secara maksimal untuk proses pengecatan.

2. Surface Preparation Pekerjaan utama yang dilakukan pada tahap ini adalah blasting, dengan kegunaan utama menghilangkan kontaminasi atau pencemaran dari dasar menghapus rekat erat, tahan kimia, kotoran dsb serta berguna untuk menyiapkan permukaan dengan jalan menaikkan tingkat kekasaran sehingga pengecatan menjadi efektif.

3. Paint Preparation Paint preparation merupakan tahapan persiapan sebelum dilakukan pengecatan, proses mixing yaitu pencampuran cat.

4. Paint Application Setelah proses pengecatan harus dilakukan pemeriksaan terhadap hasil pengecatan.

Pelaksanaan pengecatan terdiri dari 3 langkah yang harus diurutkan sesuai fungsinya masing-masing, diantaranya adalah :

1. Lapisan pertama. Pada lapisan pertama, jenis cat yang dipakai adalah jenis cat dasar. Fungsi cat dasar adalah untuk melindungi permukaan logam agar tidak berkarat atau rusak.

2. Lapisan Kedua. Pada lapisan kedua, jenis cat yang digunakan adalah jenis cat Anti Corrosion (AC), berfungsi sebagai penebal agar serangan yang datang dari luar (excess) dapat dicegah dan untuk mencegah terjadinya korosi.

3. Penyemprotan: powder coating yang telah diberi muatan elektostatis di semprotkan kepada objek yang akan dilapisi. Setelah benda melalui salah satu proses tersebut diatas kemudian benda yang telah terlapisi powder coating dimasukan kedalam oven, tujuannya untuk melelehkan dan menyatukan partikel bubuk sehingga membentuk lapisan-lapisan yang halus yang melapisi objek atau benda kerja. Selain dimaksudkan untuk memproteksi benda kerja atau logam, coating juga berfungsi untuk memperindah penampakan permukaan. Thermoplastic; material bubuk ini akan mengalami pencairan jika mendapat perlakuan panas. jenis material thermoplastic Polyethylene.

Pengelolaan Kegiatan

Kegiatan pengabdian masyarakat ini dikelola secara kelompok antara tim Pengabdian Masyarakat STTW dan lembaga Posyantek Cipta Karya. Lingkup pengelolaan tersebut meliputi kapasitas jumlah bahan baku utama, tenaga kerja dan juga pembiayaan operasional lainnya. Sehingga pihak kelurahan Serengan hanya menyiapkan gerobak sampah yang rusak tersebut dengan diantar dan diambil di bengkel mitra yang ditunjuk.

\section{Pemantauan dan Indikator Hasil Kinerja}

Kualitas keberhasilan program kegiatan ini meliputi manajemen birokrasi pemerintahan kelurahan kelurahan Serengan mampu bersinergi terhadap pihak pembaga pendidikan STTW dan juga mitra bisnis kelembagaan. Kualitas hasil pengerjaan 
perbaikan gerobak sampah ini mengacu pada analisa volume bak sampah, kapasitas kemampuan menariknya, serta daya tahan lapisan pengecatannya. Keunggulan yang diharapkan dari perbaikan metode tumpang dan pengecatan powder coating ini adalah bahwa gerobak sampah menjadi lebih aman, nyaman untuk operatornya dan mampu menjadikan lebih bersih dan sehat. Disamping itu juga mampu menambah motivasi petugas sampah dan memastikan kesadaran masyarakat dalam gemar membuang sampah pada tempatnya menuju kesehatan, kebersihan bersama.

\section{HASIL DAN PEMBAHASAN}

Hasil luaran kegiatan pengabdian perbaikan gerobak sampah ini adalah 2 unit melalui proses pembongkaran, pengelasan juga pengecatan ulang. Gerobak sampah ini berukuran $160 \mathrm{~cm}$ panjangnya, $100 \mathrm{~cm}$ tingginya dan $80 \mathrm{~cm}$ lebarnya. Permukaan alas yang berukuran $80 \times 160 \mathrm{~cm}$ atau luas $12800 \mathrm{~cm}^{2}$ diperkuat dengan penambahan lembaran besi dengan ketebalan $1.5 \mathrm{~mm}$. Pemasangannya dengan pengelasan titik di setiap permukaan kerangka bagian bawahnya. Sedangkan pengecatan ulang permukaan sisi kiri dan sisi kanan berukuran 160x100 cm serta bagian sisi depan dan belakang berkuran 100x80cm diawali dengan pelapisan dasar jenis epoxy abu-abu. Sedangkan finishing pengecatan menggunakan jenis powder coating dengan selisih waktu tahapan proses setiap 20 menit. Hasil perbaikan yang dicapai dapat dijelaskan pada gambar dibawah ini.

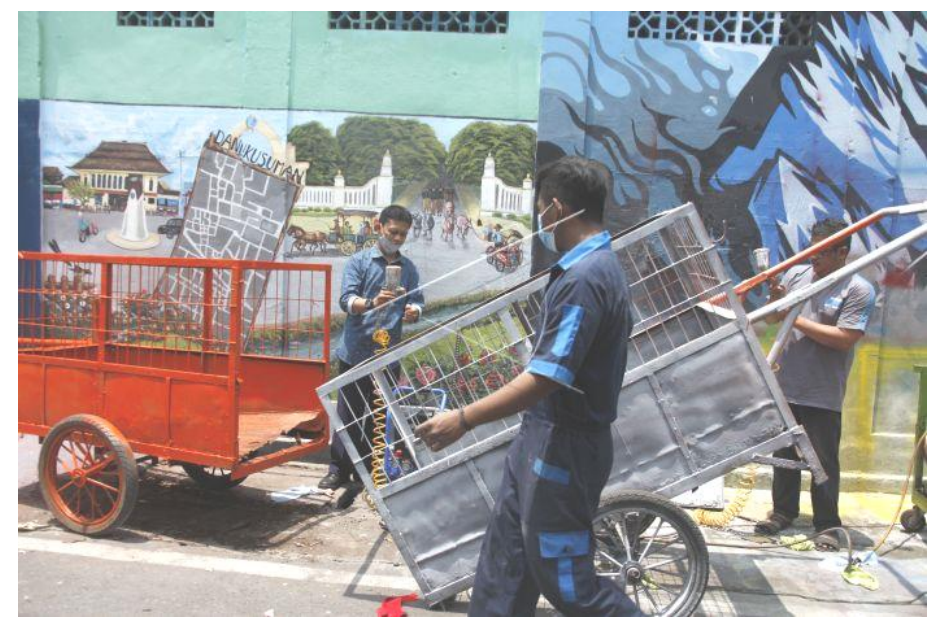

Gambar 4. alat 2 unit gerobak sampah yang sudah diperbaiki

Pembahasan terkait hasil pengabdian masyarakat dalam perbaikan 2 gerobak sampah ini dapat dianalisis secara prinsip kebutuhan kegiatan dan waktu dijelaskan pada tabel 1 dibawah ini.

Tabel 1. Kebutuhan waktu pengerjaan perbaikan dan pengecatan 2 gerobak sampah

\begin{tabular}{llll}
\hline No & \multicolumn{1}{c}{ Tahapan } & Kualitas & Waktu \\
\hline 1 & Perbaikan & & \\
& $\begin{array}{l}\text { Cek kerangka dasar } \\
\text { Penggantian kerangka dasar }\end{array}$ & $\begin{array}{l}\text { Keropos } \\
\text { kotak }\end{array}$ & 90menit \\
& $\begin{array}{l}\text { Penyambungan kerangka dasar dengan lembaran alas } \\
2\end{array}$ & las titik & 90 menit \\
& Pengecatan & & \\
& Meratakan permukaan hasil penyambungan & Gerinda & 90menit \\
& Cat dasar & Epoxy & 45menit \\
& Cat anti karat & 2 kali & 20menit \\
& Cat powder & 20menit & 25menit \\
\hline
\end{tabular}


Proses pengerjaan perbaikan alas terdiri dari 4 hal membutuhkan waktu 4 jam. Diawali dari pengecekan kekuatan tekan kerangka dasar dengan dipukul menggunakan palu. Ternyata ditemukan banyak yang terlepas pengelasannya dan ada beberapa yang keropos. Selanjutnya adalah penggantian kerangka dasar yang baru mengunakan bahan besi hollow 20x30mmx1mm dengan penyambungan las titik. Langkah yang ke tiga adalah penyambungan kerangka dasar dan alas dengan menggunakan lembaran besi yang ditekuk pada bagian sisi samping kiri dan kanan sepanjang $15 \mathrm{~cm}$ dan diperkuat dengan dilas listrik. Tahapan perbaikan yang terakhir adalah finishing pengecekan kesikuan dan kerataan permukaan dasar gerobak tersebut.

Waktu yang dperlukan proses pengecatan gerobak sampah ini adalah 3 jam. Pengerjaan pertama adalah dengan meratakan permukaan hasil pengambugan menggunakan kikir dan gerinda serta amplas. Selanjutnya dilakukan pengecatan dasar dengan jarak semprot berkisar $20 \mathrm{~cm}$ dengan tekanan pembukaan spray separuh. Pengerjaan penyemprotan dilakukan selama 3 kali dengan selisih jeda 15 menit yang bertujuan untuk memperkuat rekatan cat ke media. Pengerjaan dilanjutkan dengan penyemprotan cat pelindung korosi dengan interval waktu yang juga sama. Dan pengerjaan akhir dengan penyemprotan cat powder dari material thermoplastic Polyethylene.

\section{KESIMPULAN}

Berdasarkan hasil kegiatan pengabdian masyarakat tersebut, dapat diambil simpulan sebagai berikut :

1. Gerobak sampah manual 2 unit tersebut telah selesai perbaikan dan diserahkan serta bisa digunakan kembali secara aman dan nyaman bagi kesehatan petugas sampah dan masyarakat kelurahan serengan.

2. Waktu yang diperlukan untuk proses perbaikan alas dan pengecatan sistem powder coating pada 2 buah gerobak sampah tersebut adalah 7 jam.

\section{UCAPAN TERIMA KASIH}

Kepada LPPM STTW Surakarta diucapan terima kasih atas dukungan dalam pelaksanaan kegiatan ini secara lancar. Serta ucapan terima kasih atas peran aktif kepada semua civitas akademika dan pihak mitra Posyantek Kecamatan Serengan Cipta Karya serta pihak kelurahan serengan kota surakarta.

\section{DAFTAR PUSTAKA}

[1] Supriyono, dkk, Analisa Pengaruh Suhu Pengovenan Terhadap Daya Rekat dan Kekuatan Lapisan pada Pengecatan Serbuk, Jurnal TeknikMesin Univeristas Gunadarma, Jakarta, Indonesia, 2018, ISSN 14114143.

[2] Islahudin N, Teknologi Proses Pengecatan Mengunakan Sistem Atomisasi pada Produk Berbahan Plastik di Industri Perakitan Sepeda Motor, Jurnal SINTEK : Jurnal Mesin Teknologi, Fakultas Teknik Industri Universitas Dian Nuswantoro, Semarang, Indonesia, Volume 13 No1, 2019, ISSN 2088-9038, e-ISSN 2549-9645

[3] Ariany Z, Kajian Reparasi Pengecatan pada Lambung Kapal (Studi Kasus KM. Kirana 3), Jurnal TEKNIK, Universitas Diponegoro Semarang, Indonesia, 35 Vol 1, hal 27-32 2014, ISSN 0852-1697. 
[4] Santoso D, Analisa dan Evaluasi Jumlah Peralatan Persampahan di Kelurahan Pucang Sawit, Tugas Akhir Ahli Madya Jurusan Teknik Sipil Fakultas Teknik Universitas Sebelas Maret Surakarta, Indonesia, 2009.

[5] Atmaji D,P Pengaruh Tegangan Proteksi dan Ketebalan Cat terhadap Kekuatan Adhesi dan Permeabilitas Coating dalam Pengujian Cathodic Disbonding pada Baja API 5L Grade B di Lingkungan Air Laut, Tugas Akhir Strata 1, Jurusan Teknik Material dan Metalurgi, Institut Teknologi Sepuluh Nopember, Surabaya, Indonesia, 2016.

[6] Muhammad M M, Pengaruh Komposisi Pelarut dan Ketebalan Cat Epoksi terhadap Daya Lekat dan Tingkat Pelepuhan (Blistering) pada Lingkungan NaCL yang Diaplikasikan pada Baja Karbon, Tugas Akhir Strata 1, Jurusan Teknik Material dan Metalurgi, Institut Teknologi Sepuluh Nopember, Surabaya, Indonesia, 2015. 